\title{
REMOTE AREA RADIATION MONITORING (RARM) ALTERNATIVES ANALYSIS
}

\author{
R. L. Nelson \\ CH2M HILL Hanford Group, Inc. \\ Richland, WA 99352 \\ U.S. Department of Energy Contract DE-AC27-99RL14047

$\begin{array}{llll}\text { EDT/ECN: } & \text { DRF } & \text { UC: N/A } & \\ \text { Cost Center: } & \text { N/A } & \text { Charge Code: } & \text { N/A } \\ \text { B\&R Code: } & \text { N/A } & \text { Total Pages: } & 21\end{array}$

Key Words: Remote Area Radiation Monitoring, RARM, Waste Transfer Line, Alternatives Analysis

Abstract: The Remote Area Radiation Monitoring (RARM) system will be used to provide real-time radiation monitoring information to the operations personnel during tank retrieval and transfer operations. The primary focus of the system is to detect potential anomalous (waste leaks) or transient radiological conditions.

TRADEMARK DISCLAIMER. Reference herein to any specific commercial product, process, or service by trade name, trademark, manufacturer, or otherwise, does not necessarily constitute or imply its endorsement, recommendation, or favoring by the United States Government or any agency thereof or its contractors or subcontractors.

Printed in the United States of America. To obtain copies of this document, contact: Document Control Services, P.O. Box 950, Mailstop H6-08, Richland WA 99352, Phone (509) 372-2420; Fax (509) 376-4989.

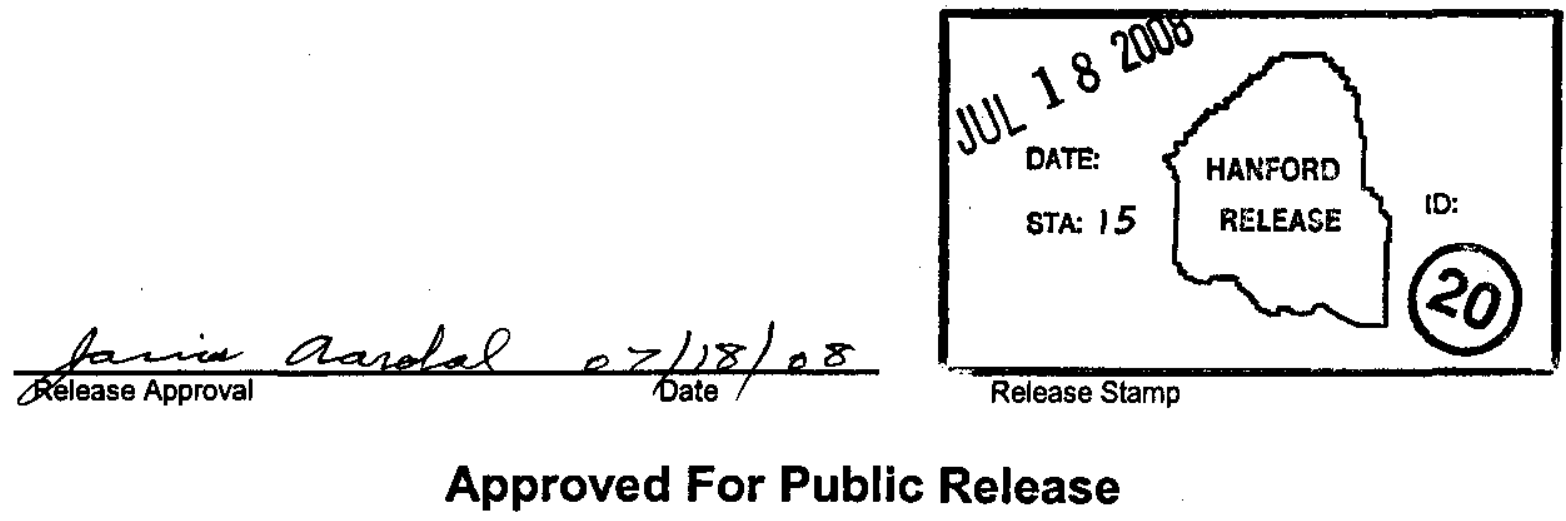




\begin{tabular}{|c|c|c|c|}
\hline \multicolumn{2}{|r|}{$\begin{array}{l}\text { Tank Farm Contractor (TFC) } \\
\text { RECORD OF REVISION }\end{array}$} & $\begin{array}{l}\text { (1) Document Number: } \\
\text { RPP-BPT-36115 }\end{array}$ & Page 1 . $f 2$ \\
\hline \multicolumn{4}{|c|}{$\begin{array}{l}\text { (2) Title: } \\
\text { Remote Area Radiation Monitoring (RARM) Alternatives Analysis }\end{array}$} \\
\hline \multicolumn{4}{|c|}{ Change Control Record } \\
\hline \multirow{2}{*}{$\begin{array}{c}\text { (3) } \\
\text { Revision }\end{array}$} & \multirow{2}{*}{ (4) Description of Change - Replace, Add, and Delete Pages } & \multicolumn{2}{|c|}{ Authorized for Release } \\
\hline & & \multirow{2}{*}{ 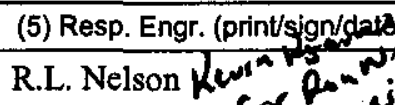 } & \multirow{2}{*}{ 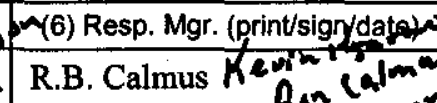 } \\
\hline 1 RS & Complete revision. & & \\
\hline
\end{tabular}


From:

Sent:

To:

Subject:
Kjarmo, Kevin J

Friday, July 18, 2008 8:30 AM

Aardal, Janis D

FW: RARM AA Record of Revision

From: Nelson, Ronald $\mathrm{L}$

Sent: Friday, July 18, 2008 8:27 AM

To: Kjarmo, Kevin J

Subject: RE: RARM AA Record of Revision

Yes.

Ron

From: Kjarmo, Kevin J

Sent: Friday, July 18, 2008 7:41 AM

To: Nelson, Ronald L

Subject: RARM AA Record of Revision

I have to do a Record of Revision for the AA. May I sign it on your behalf?

Kevin 


\title{
Remote Area Radiation Monitoring System
}

\section{Alternatives Analysis}

Prepared by

\author{
R. L. Nelson \\ CH2M HILL Hanford Group, Inc.
}

July 2008 


\section{SIGNATURE PAGE}

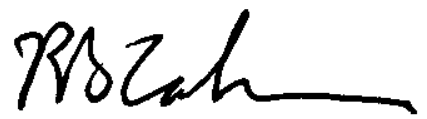

R. B. Calmus

Closure \& Facility Projects

CH2M HILL Hanford Group, Inc.

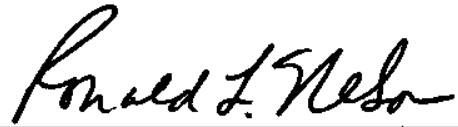

R. L. Nelson

Chief Information Officer

CH2M HILL Hanford Group, Inc.

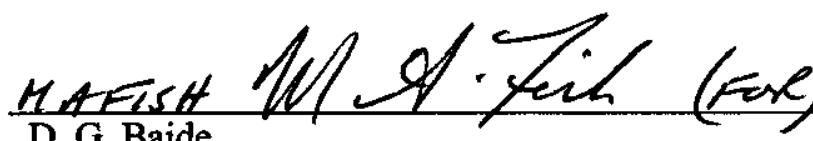

D. G. Baide

Retrieval/Closure System Engineering

CH2M HILL Hanford Group, Inc.

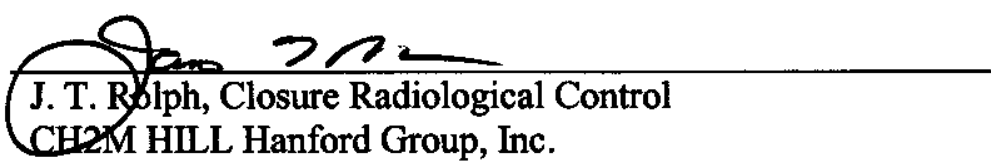

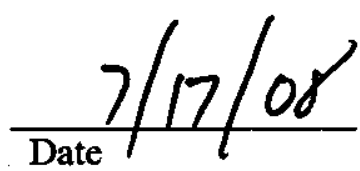

$\frac{07 / 16 / 08}{\text { Date }}$

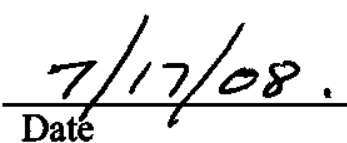

$7 / 17 / 08$ 


\section{REVISION LOG}

\begin{tabular}{|l|l|l|}
\hline Date & Revision Description & Changed By \\
\hline $04 / 30 / 2008$ & Initial Release & A. G. Dodge \\
\hline $07 / 15 / 08$ & Criteria ranking analysis added to document & R. L. Nelson \\
\hline
\end{tabular}




\section{TABLE OF CONTENTS}

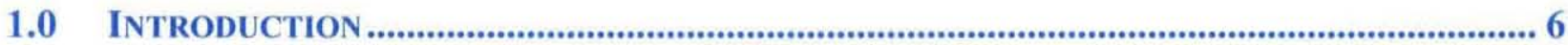

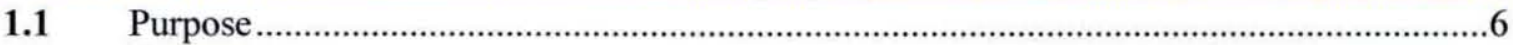

$1.2 \quad$ Scope

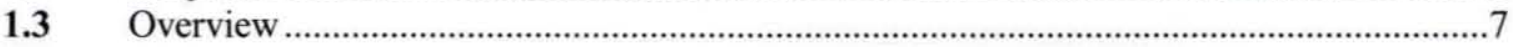

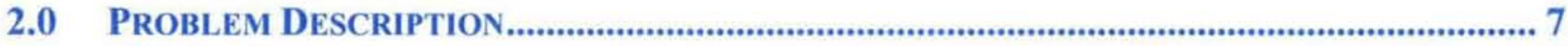

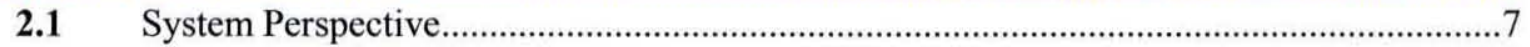

2.2 System Functions .............................................................................................................

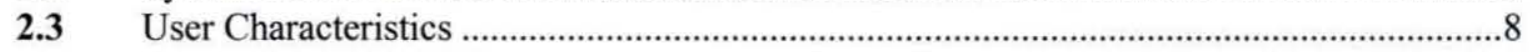

2.4 Constraints, Assumptions, and Dependencies...................................................................

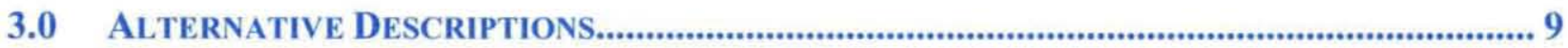

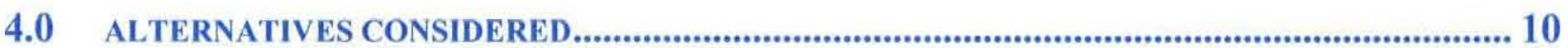

4.1 Alternative 1 - AreaRAE Gamma ${ }^{\mathrm{TM}}$ monitor manufactured by RAE Systems ................10

4.2 Alternative 2 -Model 14C Survey Meter ${ }^{\mathrm{TM}}$ manufactured by Ludlum Measurements, Inc.

4.3 Alternative 3 - Matrix RMU ${ }^{\mathrm{TM}}$ manufactured by Thermo Fisher Scientific, Inc..................12

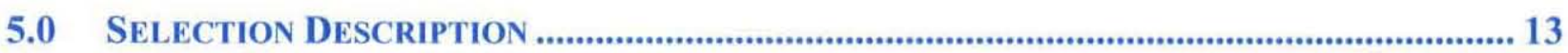

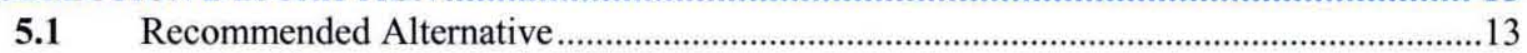

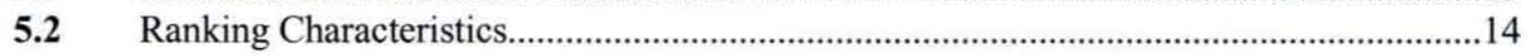

6.0 IMPLEMENTATION DESCRIPTION..................................................................................... 16

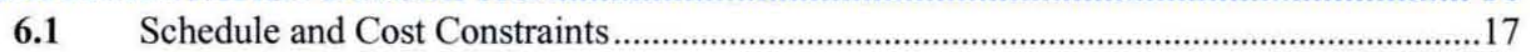

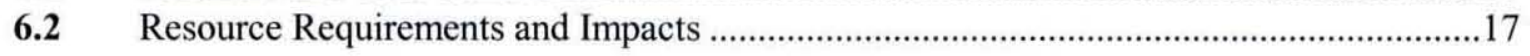

7.0 CosT JUSTIFICATION .......................................................................................................... 17

7.1 Development and Conversion Costs .............................................................................17

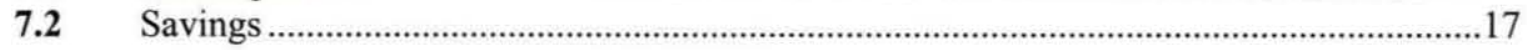

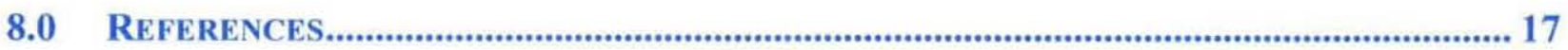




\section{LIST OF ACRONYMS}

$\begin{array}{ll}\text { COTS } & \text { Commercial off-the-shelf } \\ \text { DSA } & \text { Documented Safety Analysis } \\ \text { EPD } & \text { Electronic Personal Dosimeter } \\ \text { HISI } & \text { Hanford Information Systems Inventory } \\ \text { HLAN } & \text { Hanford Local Area Network } \\ \text { LMSI } & \text { Lockheed Martin Services, Inc. } \\ \text { NRTL } & \text { Nationally Recognized Testing Laboratories } \\ \text { PFWR } & \text { Plant Forces Work Review } \\ \text { RARM } & \text { Remote Area Radiation Monitoring } \\ \text { RMU } & \text { Remote Mobile Unit } \\ \text { SQL } & \text { Structured Query Language } \\ \text { TFC } & \text { Tank Farm Contractor }\end{array}$




\subsection{INTRODUCTION}

The Remote Area Radiation Monitoring (RARM) system will be used to provide real-time radiation monitoring information to the operations personnel during tank retrieval and transfer operations. The primary focus of the system is to detect potential anomalous (waste leaks) or transient radiological conditions. This system will provide mobile, real-time radiological monitoring, data logging, and status at pre-selected strategic points along the waste transfer route during tank retrieval operations. The system will provide early detection and response capabilities for the Retrieval and Closure Operations organization and Radiological Control personnel.

The RARM system is listed in the Hanford Information Systems Inventory (HISI) as system \#2217. The completion of the Software Quality and Safety Checklist in HISI determined the following results for the RARM system.

Table 1-1. RARM System Level/Risk

\begin{tabular}{|l|l|}
\hline Measure & Rating \\
\hline Business Category: & Engineering/Scientific \\
\hline Software Type: & Acquired Software (COTS) \\
\hline Safety Software: & Yes \\
\hline Safety Software Classification: & Safety and Hazard Analysis Software and Design Software \\
\hline Grading Level: & A \\
\hline Quality Affecting: & Yes \\
\hline Key System: & N/A \\
\hline Controlled Use: & No \\
\hline Controlled Use Exemptions: & N/A \\
\hline
\end{tabular}

\subsection{Purpose}

This alternatives analysis has been developed for a Tank Farm Contractor (TFC) company-sponsored initiative to improve radiological monitoring for tank retrieval and transfer operations. The RARM system will allow mobile, wireless radiation monitors to provide remote logging of radiation level data from strategic positions along waste transfer routes. The data recorded will be logged and displayed. The RARM application will be used by TFC employees, and other authorized personnel responsible for inspection, monitoring, trending and reporting functions required for retrieval system operation.

\subsection{SCOPE}

The TFC reviewed three radiological monitoring systems in this alternatives analysis. These systems include:

- AreaRAE Gamma ${ }^{\mathrm{TM}^{1}}$ monitor manufactured by RAE Systems, Inc.

- Model 14C Survey Meter ${ }^{\mathrm{TM}^{2}}$ manufactured by Ludlum Measurements, Inc.

\footnotetext{
${ }^{1}$ AreaRAE Gamma is a trademark of RAE Systems Inc.

${ }^{2}$ Model 14C Survey Meter is a trademark of Ludlum Measurements, Inc.
} 
- Matrix RMU ${ }^{\mathrm{TM}}{ }^{3}$ manufactured by Thermo Fisher Scientific, Inc.

\subsection{OVERVIEW}

On July 27, 2007 the TFC reported that a mixed radioactive and chemical waste leak had occurred in the vicinity of the 241-S-102 tank retrieval pump located in the 200 West area of the Hanford Site. The event was discovered during an investigation into the cause of high radiation readings noted earlier that morning following a waste transfer. The magnitude of the event was not understood for several hours. Subsequent analysis indicated that a spill of between 85 and 115 gallons of mixed waste had occurred.

Prior to this event, the TFC was exploring technologies to reduce the risk to personnel of exposure to hazards. As a result of the spill, the immediate concern became exposure of personnel to radiation and toxic chemicals, thus the RARM system schedule was expedited.

The objective of the RARM system is to provide a remote, real-time radiation monitoring system. The system will detect potential anomalous (waste leaks) or transient radiological conditions during tank retrievals. The system will provide both an audible and visual warning to personnel in the vicinity. The system will also provide radiological status of the tank transfer conditions to allow for early detection and response capabilities.

\subsection{PROBLEM DESCRIPTION}

The major function of the system is to provide early detection of potential anomalous (waste leaks) or transient radiological conditions during tank retrieval and transfer operations. The system must reduce the risk of personnel exposure to potentially hazardous radiation levels by providing both a local and remote warning of increased radiation levels during waste transfers. The RARM system needs to record radiation level data at specified points along the waste transfer route and transmit the logged data to a central monitoring base for trending, analysis, and alarm notification.

\subsection{SySTEM PERSPECTIVE}

The RARM system will consist of two major components, a battery-powered remote monitoring unit (RMU) with wireless communication capabilities and a base receiver station. The system should be able to operate in both a stand-alone mode with the RMUs and base station or in a network configuration. The RMUs will contain a detector, preferably an electronic personal dosimeter (EPD), which will measure the gamma dose rates, a radio to transmit the readings to the base station, local audible and visual alarms, and a controller to manage the units' functions. Additionally, the RMU units will provide a status indication for both normal and malfunction conditions.

The base computer unit component will consist of the hardware and software necessary for communicating with the RMU units and for monitoring and logging the readings.

In the network configuration, the RMUs will be capable of communicating with the Hanford Local Area Network (HLAN) via a wireless access point, network server, and a web-based application. The network configuration will have all of the functionality of the stand-alone configuration.

\subsection{SYSTEM FUNCTIONS}

\footnotetext{
${ }^{3}$ Matrix RMU is a trademark of Thermo Fisher Scientific Inc.
} 
The Retrieval and Closure Operations organization has specified several requirements for the RARM system. Weights for each requirement range in value from 1 to 10 , with 10 being the highest, thus most important to the system. Retrieval and Closure Operations personnel reviewed the requirements and assigned importance to each.

The RARM system will provide the following functions:

- Remote Monitoring of Gamma Radiation Levels

- Mobile Radiation Monitoring Units

- Support Wireless Communication

- Target and Area Monitoring

- Hanford Experience with Vendor Technology for Gamma Monitoring

- Compatibility with Current Equipment and Infrastructure

- A Cost Effective Solution

\subsection{USER CHARACTERISTICS}

The RARM application will be used by TFC employees, and other authorized personnel responsible for inspection, monitoring, trending and reporting functions required for retrieval system operation. The TFC employees and managers will periodically monitor the radiation level data logged by the application. The level of computer knowledge varies greatly among users. As a result, the RARM system needs to be simple to use.

\subsection{CONSTRAINTS, ASSUMPTIONS, AND DEPENDENCIES}

\subsubsection{Assumptions}

- The RARM system will be compliant with the TFC contractual requirements.

- A task force of subject matter experts in source data and requirements will be available, as required.

- Vendor consultants will be available to resolve technical and administrative issues in order to meet schedule commitments, as required.

- No legal issues, security requirements, or other technical issues prevent deployment of the RARM system.

- Required equipment and critical labor resources are available to meet schedule commitments.

- Plant Forces Work Review (PFWR) will not delay scheduled commitments for field work.

- The RARM system will use existing infrastructure for deployment including network, wireless, and server hardware.

- Target date for system requirements development, analysis of system alternatives, and system testing is April 30, 2008.

- Target date for complete field deployment for Tank Farm use is July 31, 2008.

- Selected vendor will be able to meet the requirements as specified in RPP-SPEC-25400, Revision 3.

- Critical path to meet delivery dates will be the procurement specification, detector enclosure configuration, environmental testing, NRTL electrical certification, and field mounting structures and integration with Retrieval Projects field activities. 


\subsubsection{Dependencies}

- $\quad$ RMU design changes and manufacturing

- Current computer software adequate

- Funding commitment and authorization

- Resource allocation and priority

- Resource skill set availability

\subsubsection{Constraints}

- System cost must be within the budget

- System must be available by scheduled due dates

\subsection{ALTERNATIVE DESCRIPTIONS}

All of the alternatives were evaluated based on assumptions concerning the major components of the system. The assumptions made for each component include:

\subsubsection{Detector Assumptions}

- Commercial off-the-shelf (COTS) product

- Rechargeable or replaceable battery power supply

- Range of gamma detection between one (1) $\mathrm{mR} / \mathrm{hr}$ and $50,000 \mathrm{mR} / \mathrm{hr}$ for photon energy range $60 \mathrm{KeV}$ to $2 \mathrm{MeV}$

- Can be calibrated or configured to necessary standards and parameters

- Arrives with calibration certificates

- Parts are labeled with serial numbers

\subsubsection{RMU Assumptions}

- Enclosure is a COTS product

- COTS product can be modified without degradation of protection capability

- Unit is mobile and can be handled and transported by one (1) person

- Unit weighs less than 40 pounds without battery installed

- Unit is battery operated with quick disconnect capability for battery changeout

- Capable of operating 24 hours a day, seven days a week

- Batteries can be operated for 30 days without recharge

- Field unit cost is between $\$ 5,000-\$ 10,000$

- Includes audio alarm

- Includes visual alarm

- Modular construction

- Hanford craft personnel will maintain units

- Units will be rated for outdoor use

- Units can operate in an ambient temperature range of $-25^{\circ} \mathrm{F}$ to $+115^{\circ} \mathrm{F}$

- Units can operate in a solar radiation environment of 900 Langleys

- Compatible with $900 \mathrm{MHz} / 802 \mathrm{~b} / \mathrm{g}$ wireless communication 
- Capable of target and area monitoring

\subsubsection{Base Computer Unit Assumptions}

- COTS product with software pre-installed

- Functions in a stand alone mode

- Provides data display

- Provides data collection

- Provides data storage

- Supports multiple detectors

- Supports multiple types of detectors

- Supports grouping detectors by activity

- Supports multiple activities

- Monitors multiple activities simultaneously

- Standard base computer unit software is capable of monitoring up to 32 RMU units

\subsubsection{Network Assumptions}

- Server based software products are available

- Receiving/Transmitting hardware is available for polling field RMUs

- Server mode compatible with Structured Query Language (SQL)

\subsection{ALTERNATIVES CONSIDERED}

\subsection{ALTERNATIVE 1 - AREARAE GAMMATM MONITOR MANUFACTURED BY RAE SYSTEMS}

\subsubsection{Pros}

- Can also monitor up to four gases

- Can transmit up to 2 miles to base computer unit (extendable with RAELink2 repeaters)

- Standard desktop computer or laptop can be used as base computer unit

- Can add optional solar power source to RMU

\subsubsection{Cons}

- Gamma detector only designed for environmental monitoring

- Detector heavy and awkward to handle in other than one (1) position

- Must be certified to meet temperature requirements

- Only runs 24 hours without recharging batteries

- Addition of optional solar power source increases cost and weighs $\sim 70$ pounds

\subsubsection{Assumptions}

- Detects gamma radiation

- Includes audio and visual alarms

- Supports wireless communication

- Base computer unit displays logged data

- Remote RMU 
- Battery operated

- Weather resistant construction

- Standard base computer unit software is capable of monitoring up to $32 \mathrm{RMU}$ units

\subsubsection{Dependencies}

AC power source necessary for continuous monitoring

\subsubsection{Risk Assessment}

Alternative 1 is considered medium risk, medium probability for success. The vendor is located regionally (Moses Lake, Washington) and is currently doing business at Hanford in the Industrial Hygiene area. Having a local based vendor would be convenient from a relationship perspective, but the product line itself is limited by factors that would impact project deliverables. They are:

- Detector is designed for gamma environmental monitoring and would require redesign to meet intended gamma detection ranges.

- Detector casing is heavy and primarily configured to be placed in horizontal position inside the RMU box without physical locking mechanisms for mobility and positioning to target needed areas.

- Standard RMU does not meet operating temperature requirement and would require environmental testing to meet Hanford standards

- Standard RMU exceeds unit weight requirement of 40 pounds by itself making movement of the units difficult and resource intensive

- Software is limited to a maximum of 64 detectors per software instance which significantly constrains the expansion of the system to other TFC applications

\subsection{Alternative 2 -MOdEl 14C SURVEY METER $^{\text {TM }}$ MANUFACTURED By LUdLUM MEASUREMENTS, INC.}

\subsubsection{Pros}

One thousand hour battery life

\subsubsection{Cons}

- Must be certified to meet temperature requirements

- Does not support wireless communications

\subsubsection{Assumptions}

- Detects gamma radiation

- Includes audio and visual alarms

- Displays radiation level on unit

- Base computer unit displays logged data

- Remote RMU

- Battery operated

- Weather resistant construction

- Standard base computer unit software is capable of monitoring up to $32 \mathrm{RMU}$ units 


\subsubsection{Dependencies}

Wired communication necessary for operation

\subsubsection{Risk Assessment}

Alternative 2 is considered high risk, low probability for success and this alternative should be excluded based on the lack of wireless capability for a mobile system. The vendor has extensive experience in the industry, but the product line itself is limited by factors that would impact project deliverables. They are:

- Wireless communication is not supported and would not meet the primary goal of a mobile radiation detection system

- Standard RMU does not meet operating temperature requirement and would require environmental testing to meet Hanford standards.

\subsection{ALternative 3 - MATrix RMU ${ }^{T M}$ MANUFACTUREd BY THERMo Fisher SCIENTIFIC, INC.}

\subsubsection{Pros}

- Can transmit up to $3000 \mathrm{ft}$ to base computer unit with standard antenna or up to 6 miles with a high gain antenna.

- Have both stand alone and network versions of software products

- Projected sixty day battery life under normal operating conditions

- Software monitors other vendor products

- Software is not limited to the number of detectors per software instance which allows for significant expansion of the system to other TFC applications

- Three (3) years experience with similar prototype vendor system

\subsubsection{Cons}

- Must be certified to meet temperature requirements

- Must be certified to Hanford site electrical requirements (NRTL)

- Requires custom laptop (VP-SaT ${ }^{\mathrm{TM}}$ ) unit to operate in standalone mode

\subsubsection{Assumptions}

- Detects gamma radiation

- Includes audio and visual alarms

- Displays radiation level on unit

- Supports wireless communication

- Base computer unit displays logged data

- Remote RMU

- Battery operated

- Weather resistant construction

- Standard base computer unit software is capable of monitoring up to $32 \mathrm{RMU}$ units

\subsubsection{Dependencies}

None 


\subsubsection{Risk Assessment}

Alternative 3 is considered low risk, high probability for success. The TFC is currently using a prototype system created by this vendor over the last 3 years. The vendor has extensive experience in the industry, but the product line does have identified factors that would impact project deliverables. They are:

- Standard RMU does not meet operating temperature requirement and would require environmental testing to meet Hanford

- Standard RMU is not certified to Hanford site electrical requirements (NRTL)

\subsection{SELECTION DESCRIPTION}

Alternatives considered included commercially available equipment that met most of the requirements with the least amount of redesign. The time constraints placed on the project dictate as few modifications to the monitor as possible.

The requirements for the RARM system are defined in the functional design requirements document (RPP-36117 Rev.0, Remote Area Radiation Monitoring System Functional Design Requirements). A panel of subject matter experts evaluated the requirements and developed the weights. The panel also graded the alternatives.

\subsection{RECOMMENDED ALTERNATIVE}

The recommended alternative is the third alternative, the Matrix RMUTM. These units, combined with the Thermo Fisher Scientific Inc. ViewPoint ${ }^{\mathrm{TM}}{ }^{4}$ software, provide the best overall solution for the RARM system. The evaluation of all of the alternatives is explained below.

The Matrix RMUTM is the only alternative that met all of the conceptual requirements. These units are mobile, wireless units that can remotely monitor specific areas or a target area. The units are compatible with existing site equipment. Thermo Fisher Scientific Inc. equipment is currently used for gamma detection. The units also provide a cost effective solution.

The AreaRAE Gamma ${ }^{\mathrm{TM}}$ monitor alternative met the conceptual requirements but posed some additional problems in reality. The monitors are mobile, wireless units that can remotely monitor specific areas or a target area. These monitors will require extensive battery maintenance or an AC power supply. Supplemental solar power supplies are available for an additional cost, but the solar units weigh 70 pounds.

The Model 14C Survey Meter ${ }^{\mathrm{TM}}$ alternative does not support wireless communication. Although these meters met the other conceptual requirements, trying to upgrade the meters is not cost effective. A modification to these meters as fundamental as adding wireless communication would jeopardize the schedule.

\footnotetext{
${ }^{4}$ ViewPoint software is a trademark of Thermo Fisher Scientific Inc.
} 


\subsection{RANKING CHARACTERISTICS}

The following ranking chart has been developed for the RARM system.

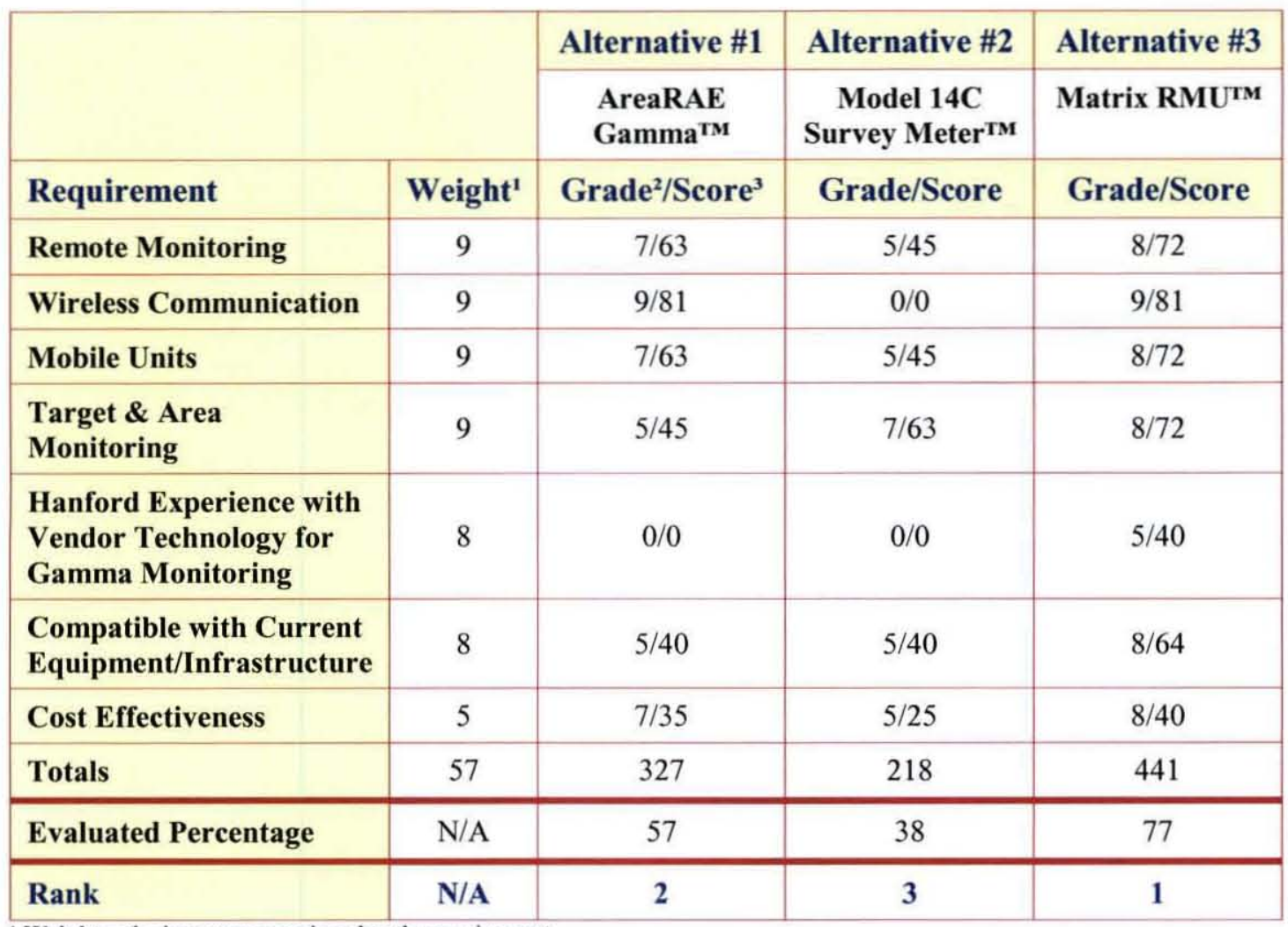

' Weight $=$ the importance assigned to the requirement.

${ }^{2}$ Grade $=$ the alternative's calculated score for the requirement. (Grades $\left.1-10\right)$

${ }^{3}$ Score $=$ the alternative's calculated score for the requirement. (Score $=$ Weight $x$ Grade)

The evaluated percentage for each alternative is formulated by (total of scores/total of weights) $\mathrm{x} 10$.

- $\quad$ AreaRAE Gamma ${ }^{\mathrm{TM}}$ is $(327 / 57) \times 10=57$.

- Model $14 \mathrm{C}$ Survey Meter ${ }^{\mathrm{TM}}$ is $(218 / 57)$ x $10=38$.

- Matrix RMUTM is $(441 / 57) \times 10=77$, and this is the recommended alternative.

\subsubsection{Ranking Analysis}

The evaluated percentage for alternative \#1 is $(290 / 33) \times 10=87.8$, and this is the recommended alternative.>

\section{Remote Monitoring}

- Alternative 1: Scored a 7 (seven) due to ability to place monitors at preferred locations and monitor up to 32 instruments remotely per instance of software via a network.

- Alternative 2: Scored a 5 (five) due to ability to place monitors at preferred locations, but does not have monitoring capable software to read remotely. 
- Alternative 3: Scored an 8 (eight) due to ability to place monitors at preferred locations and monitor up to 64,000 instruments remotely on a single instance of the software via a network. In addition, allows monitoring of different device types conducive to expansion of remote monitoring capabilities in other areas such as personnel dose, chemical, air, and, physiological devices.

Wireless Communications

- Alternative 1: Scored a 9 (nine) as the system is capable of wireless communications using an RF modem transmission in a license free band.

- Alternative 2: Scored a 0 (zero) as the system is incapable of any wireless connectivity.

- Alternative 3: Scored a 9 (nine) as the system is capable of wireless communications using $802.11 \mathrm{x}$ or $900 \mathrm{Mhz}$ frequency bands.

Mobile Units

- Alternative 1: Scored a 7 (seven) as the units are mobile and can placed at needed locations. Enclosures are hardened with handles for ease of movement. Units come with local and audible alarms and do not require an attendant to monitor. Batteries must be changed out or recharged every 24 hours.

- Alternative 2: Scored a 5 (five) as the units are mobile and can be placed at needed locations. Enclosures are hardened with handles for ease of movement. Units to do not have local and audible alarms and must remain attended to monitor. Batteries must be changed out typically after 83.33 days of use.

- Alternative 3: Scored an 8 (eight) as the units are mobile and can placed at needed locations. Enclosures are hardened with handles for ease of movement. Units come with local and audible alarms and do not require an attendant to monitor. Batteries must be changed out or recharged every 30 days.

\section{Target and Area Monitoring}

- Alternative 1: Scored a 5 (five) as the system was designed general area environmental type monitoring and the gamma measurement components would need to be redesigned by the manufacturer to meet the ranges required for this application.

- Alternative 2: Scored a 7 (seven) as the system was primarily designed for target type monitoring, with some general area indications, however the device would need to be redesigned by the manufacturer for use in this application.

- Alternative 3: Scored an 8 (eight) as the system was designed for flexibility to perform both general area and target type monitoring in a variety of commercial or custom applications. No redesign of the core components would need to be done for this application. However, enclosure design must be customized to meet requirements. 


\section{Hanford Experience with Vendor Technology for Gamma Monitoring}

- Alternative 1: Scored a 0 (zero) as no vendor experience with their radiation monitoring equipment in this type of application.

- Alternative 2: Scored a 0(zero) as no vendor experience with their radiation monitoring equipment in this type of application.

- Alternative 3: Scored a 5 (five) as some vendor experience with their radiation monitoring equipment in this type of application through proof of concept pilot project. Pilot project did not perform necessary requirements-based pedigree for this application.

\section{Compatible with Current Equipment/Infrastructure}

- Alternative 1: Scored a 5 (five) as the system could be made to be compatible with our current equipment and infrastructure. However, the wireless component and software interface would require redesign by the vendor to achieve.

- Alternative 2: Scored a 5 (five) as the system could be made to be compatible with our current equipment and infrastructure. However, the wireless component and software does not currently exist and would require redesign by the vendor to achieve.

- Alternative 3: Scored an 8 (eight) as the system is currently compatible with current equipment and infrastructure and is available as commercial-off-the-shelf product.

\section{Cost Effectiveness}

- Alternative 1: Scored a 7 (seven) as the system gamma monitoring devices are significantly more expensive than the other alternatives without an enclosure. The proposed enclosure is an additional cost which is higher than the other alternatives for this application.

- Alternative 2: Scored a 5 (five) as the system gamma monitoring devices are acceptable from a cost perspective. However, no enclosure, wireless, or software exists in the product line to support this application. Estimated cost to design the support infrastructure would make this alternative more expensive than the other alternatives.

- Alternative 3: Scored an 8 (eight) as the system gamma monitoring devices are acceptable from a cost perspective. The enclosure, wireless, or software exists in the marketplace to support this application. Estimated cost to custom design the enclosure for this application is considered acceptable and makes this alternative the least cost of the alternatives.

\subsection{IMPLEMENTATION DESCRIPTION}

A prototype RMU unit has been developed. Thermo Fisher Scientific, Inc. personnel have visited the site to demonstrate their adaptation of the RARM system. This approach minimizes the risk associated with developing the application. 


\subsection{SCHEdULE AND COST CONSTRAinTS}

The development of the RARM system with the CNET 1000 unit is the most likely alternative for completing the system in the time frame specified. The original schedule requires the system to be completed prior to April 30, 2008.

\subsection{RESOURCE REQUIREMENTS AND IMPACTS}

The use of CNET 1000 unit and the ViewPoint ${ }^{\mathrm{TM}}$ software included helps ensure the RARM system can be procured and deployed on schedule and within budget. Resources necessary to develop and maintain the RARM system assessment and documentation are available. Future enhancements to the RARM system will be scheduled and budgeted for as necessary.

\subsection{COST JUSTIFICATION}

Cost justifications are described in the following subsections.

\subsection{DEVELOPMENT AND CONVERSION COSTS}

Development costs for the RARM system includes the costs associated with the wireless interface. The use of the COTS ViewPoint ${ }^{\mathrm{TM}}$ software is expected to reduce the possibility of additional costs. There will be no conversion costs from another system to the RARM system.

\subsection{SAVINGS}

The use of the COTS products for both the RMU units and the software designed for the units are expected to help expedite the deployment of the product. Additionally, procedural infrastructure and field personnel experience/familiarity with a similar prototype system will reduce implementation time and cost to deployment..

\subsection{REFERENCES}

TFC-BSM-IRM_HS-C-02, Acquired Software Implementation and Management.

RPP-36117 Rev. 0, Remote Area Radiation Monitoring System Functional Design Requirements, CH2M HILL Hanford Group. 